\title{
The Relationship between Teachers' Motivational Support and Engagement versus Disaffection
}

\author{
Hulya Guvenc ${ }^{a}$ \\ Yeditepe University
}

\begin{abstract}
The purpose of this study is to investigate relationships between students' engagement versus disaffection and their perceptions of teachers' motivational support styles. To do this a hypothesized structural model specifying the direct relationships of students' engagement and their perceptions of teachers' motivational support is used. The model, covers students' motivational regulations, as mediator variables, between students' engagement and their perceptions of teachers' motivational support styles, that is tested. Participants are 276 ninth grade high school students (148 girls and 126 boys). Data are collected by the "Effective Participation Scale," "Motivational Regulation Scale," and "Teachers' Motivational Support Scale." The fit statistics indicate that the research model provides a reasonably good fit to the data $\left(x^{2}=74.62, d f=38, p=.00, R M S E A=.086, R M R\right.$ $=.05, \mathrm{CFI}=.96, \mathrm{GFI}=.90, \mathrm{AGFI}=.92, \mathrm{NFI}=.91, \mathrm{NNFI}=.91 \mathrm{l}$. Chi-square to degrees of freedom ratio $x^{2} / \mathrm{df}=1.96$ is satisfactory. The study indicates that motivational support provided by teachers has effect on the students' motivation orientation and active class participation.
\end{abstract}

Keywords: Engagement $\bullet$ Disaffection $\bullet$ Self-determination $\bullet$ Teacher support $\bullet$ Autonomous motivation $\bullet$ Controlled motivation

a Correspondence

Assoc. Prof. Hulya Guvenc (PhD), Department of Guidance and Psychological Counselling, Faculty of Education, Yeditepe University, 26 Aḡustos Campus, Kayıșdaḡı Cad. Ataşehir, İstanbul 34755 Turkey Research areas: Instructional designs; Students' cognition and motivation Email: guvenchulyalagmail.com 
Instead of minimizing the in-class role of the teacher, student centered approaches to the learning-teaching process and increasing technological support have drawn attention to the importance of teacher's professional roles. Teachers who design and apply teaching techniques play an important role in the motivation and class participation of the students. Before examining teachers' effects on engagement and motivation, it is necessary to consider these concepts.

Together, with the emphasis on the active role of the learner in the learning process, the concept of engagement and -its opposite disaffection appear as key ideas in many theories and studies. Engagement and disaffection, determine the intensity and quality of participation when beginning and continuing the learning activities of students (Skinner, Wellborn, \& Connell, 1990). Students' active participation in the class is basically related to their engagement to learning.

The engagement concept defines the initiation of motivated action as well as the continuation of action in spite of obstacles and difficulties (Skinner, Kindermann, Connell, \& Wellborn, 2009). Students' engagement in lessons involves two dimensions: the behavioral and emotional dimensions. The behavioral dimension of engagement, involves effort, attention, and concentration during the act of learning. Engagement within the behavioral dimension may be defined as conducting the learning activity and class participation (Skinner \& Belmont, 1993). The emotional dimension of engagement reflects positive emotions such as enthusiasm, interest, and enjoyment experienced during learning. Although the opposite of engagement is lack of engagement, which defined as the absence of effort and determination, the term "disaffection" is used. The reason for this is that, in addition to the lack of engagement, disaffection involves mechanical participation where there is no mental participation and attention. Furthermore, disaffection includes negative emotional elements such as boredom, anxiety, and frustration (Skinner et al., 2009).

Engagement is an important factor concerning students' actions. Studies have indicated that engagement is a strong predictor of student success and behavior. Research has found that engagement protects students from risk-involving behavior in the learning environment (Skinner, Furrer, Marchand, \& Kindermann, 2008). Students who are engaged during learning achieve better grades as compared with the less-engaged students and are less likely to drop out. In contrast, disaffected students face many risks such as disrupting the class and dropping out (Furrer \& Skinner, 2003).

Engagement emerges as a product of motivation. Motivation is an inner power compels an individual to reach a goal and that strengthens, and directs the individual's behaviors (Başaran, 1982). Motivation is a highly complex concept. Ryan and Deci (2000) indicate that humans are not only motivated at different levels, but that their motivation orientations are different. There can be different attitudes and goals behind the motivations of individuals demonstrating the same action. For instance, the student completing the learning task assigned in class may be acting in order to achieve a reward or to avoid a punishment given by the teacher. In this case, the individual's motivation orientation is external. The student has no option but perform the task at hand. However, there are times when the pressure directing the student to perform the task does not come externally. The student may also complete the task for reasons such as avoiding a feeling of guilt, coping with shame and anxiety, or achieving positive emotions, such as pride and relaxation. This motivation orientation is referred to as "introjected." Although the student may be carrying out the task in order to avoid their own negative emotions, this orientation is also external as these emotions are external and the student has no option but to perform the task (Ryan \& Deci, 2000).

If the student is performing the task because they take pleasure in doing so, the motivation orientation is internal, and the motivation type is referred to as intrinsic motivation. Intrinsic motivation refers to the enactment of the activity for its own sake (i.e., for excitement, enjoyment, and interest that is inherent to the learning itself) (Vansteenkiste, Sierens, Soenens, Luyckx, \& Lens, 2009). In such cases, the student demonstrates a totally volitional and autonomous participation to the activity. Although of external origin, another motivation orientation, where the student participates in the activity his or her choice instead of being pressured to do so, is referred to as identification or well, internalized extrinsic motivation. Here the reason that the student performs the activity is that it serves another purpose that is important to them. The student regards the work as a means to their personal goals, while still feeling autonomy psychologically.

In summary, according to the self-determination theory, individuals' motivation conditions are positioned on a continuum extending from the highest autonomously decided motivation to controlled motivation (Vansteenkiste et al., 2009). 


\section{Internal Identification}

Introjection

Figure 1: Motivational regulation of students.

Autonomous motivation comprises intrinsic motivation and autonomously decided external motivation (identification). Controlled motivation, however, comprises introjected external motivation and external motivation. Autonomous motivation is related to cognitive and affective elements, such as the use of metacognition strategies in the learning process, effort, and persistence (Vansteenkiste et al., 2009). There is a positive correlation between autonomous motivation and success. Controlled motivation, on the other hand, is related with anxiety, failure in focusing, time management problems and underachievement (Vansteenkiste et al., 2009). Students that approach the course with controlled motivation have difficulty in engagement to the course.

Accordingly, the intrinsic motivation of the students must be targeted. If the student is motivated when the activity itself is interesting or engagement of the activity is reward, the question of "what is it that makes the activity interesting" must be answered. Setting out from the starting point that psychological impulses lie behind human behavior, Ryan and Deci (2000) respond to this question by claiming that activity assists in meeting humans' basic needs. Based on self-determination theory, Deci and Ryan (1987), indicate that humans have three basic needs: autonomy, competence, and relatedness. Humans are motivated to the extent that these needs are met.

Considering this within the context of school, competence is the students' need to understand their tasks at school. The need for relatedness expresses the student's needs for belongingness, personal support, and security in their relationships at school. The need for autonomy, however, may be defined as the students' need for space to decide on the beginning, maintenance, and reorientation of activities at school (Connell, 1990 as cited in Stefanou, Perencevich, DiCintio, \& Turner, 2004). Without doubt, the most important role in meeting the student's psychological needs in class belongs to the teacher(s).

Teachers, whose student motivation effect in class determines the reward structure and regulates the learning activities, plays an important role in student motivation not only through modeling, guidance, or expectations (Good \& Brophy, 1987), but also in meeting students' need for relatedness, competence, and autonomy. Although there is much research on the correlation between teachers' behavior and students' motivation, recent studies examining the effects of teachers' meeting the students' needs within the framework of the selfdetermination theory have attracted attention. Accordingly, how teachers ensure support for relatedness, competence, and autonomy is examined together with its effects.

The human need for relatedness is emphasized by many theories. The need for forming relationships with others, dependence, acceptance, belongingness, and trust in relationships, is native to humans. Having positive relationships, especially in the face of a difficulty, is seen as an important motivational source for the student's persistence, flexibility, and constructive actions (Furrer \& Skinner, 2003). The student's relations with their teachers especially affect emotional engagement. Students that believe their teachers accept them and think they are valuable, feel more comfortable, are happier in class, and feel happy in participating in class activities. In contrast, students who believe that their teachers do not care for them and ignore them generally feel unhappy, angry, and bored during learning activities (Furrer \& Skinner, 2003). Research shows that the quality of teacher-student relationships is related to learning products such as achievement, effort, engagement, task-goal orientation, and self-efficacy (Lynch \& Cicchetti, 1997; Midgley, Feldlauffer, \& Eccles, 1989; Ryan, Stiller, \& Lynch, 1994).

The students' need for competence can be met to the extent that the knowledge necessary for achieving goals is present. For this reason, the student's sense of competence is to a great extent connected with the structure built by the teacher. Classes where expectations are clearly defined and are consistently maintained ensure a sense of competence in students. When students know how to complete learning tasks, how to achieve goals, and what is expected of them in class, they are able to regulate their behaviors accordingly (Sierens, Vansteenkiste, Goossens, Soenens, \& Dochy, 2009). In classes where the teacher arranges the class structure in a manner that supports the students' perception of competence, engagement is high (Tucker et al., 2002) and self-regulated learning strategies are more widely employed (Sierens et al., 2009). 
Autonomy is defined as an individual's freedom to determine his or her own behavior. Teachers who support students' autonomy offer students a wide range of choices in matters such as teaching tasks, materials, and whom they should work with, thus making an effort to eliminate external control devices. Teachers that support autonomy encourage students in reflecting their own perspective to the class and avoid controlling language. Research shows that there is a high correlation between student motivation and teachers' autonomy support; a teacher's support of autonomy increases the interest in learning and selfregulated learning, it decreases anxiety about grades, and improves time management and concentration (Assor, Kaplan, \& Roth, 2002; Benita, Roth, \& Deci, 2014; Black \& Deci, 2000; Deci, Schwartz, Sheinman, \& Ryan, 1981; Sierens, et al., 2009; Vansteenkiste, Zhou, Lens, \& Soenens, 2005).

Accordingly, it is important to examine the effect that the motivational support the teacher gives the student has on student motivation and participation. This study should be practical in helping teachers and teacher educators set a positive context in the classroom to increase student engagement. Even though different studies have shown relations between these variables there is a need to examine the whole theoretical frame. Few studies have been tested with teacher-support of the effects on engagement versus disaffection (Skinner et al., 2008). The current study may provide more data about perceived teacher motivational support on perceived engagement versus disaffection. Furthermore, this study may fill the gap of not having tested the effects of students' motivational regulations between perceived teacher motivational engagement versus disaffection. The purpose of the study is to investigate relationships between students' engagement and their perceptions of teachers' motivational support style. To do this a hypothesized structural model, which specifies the direct relationships of students' engagement and their perceptions of teachers' motivational support, and students' motivational regulations as mediator variables between students' engagement and their perceptions of teachers' motivational support style is developed to be tested. Based on the theoretical notions and model described above, this research was designed to address the following hypotheses:

H1: Students' perceptions of teachers' motivational support style will be positively related to the autonomous motivation of students.

H2: Students' perceptions of teachers' motivational support style will be negatively related to the controlling motivation of students.

H3: Students' perceptions of teachers' motivational support style will be positively related to the students' engagement.

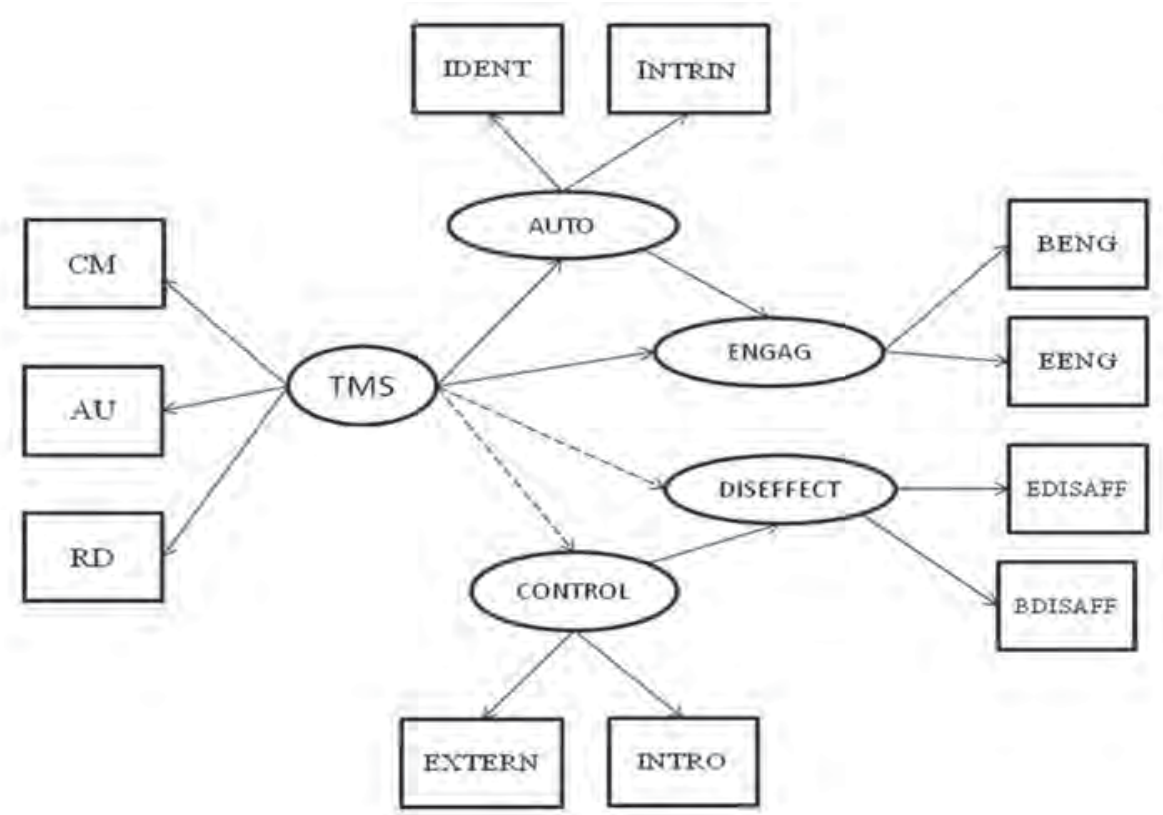

Figure 2: The theoretical model of the relationship of teachers' motivational support style with engagement versus disaffection. 
H4: Students' perceptions of teachers' motivational support style will be negatively related to the students' disaffection.

H5: Students' autonomous motivation will be positively related to the students' engagement.

H6: Students' controlling motivation will be positively related to the students' disaffection.

H7: The relationship between students' perceptions of teachers' motivational support style and students' engagement will be moderated by students' autonomous motivation.

H8: The relationship between students' perceptions of teachers' motivational support style and students' disaffection will be moderated by students' controlled motivation.

\section{Methods}

The hypothesized structural equation model is developed as a theoretical basis for explaining students' engagement and disaffection that is related to perceived teachers' motivation styles (Figure 2). The model identifies direct predictive power of independent variables (perceived teachers' motivational styles) on the dependent variables (students' motivational regulation and their engagement versus disaffection). This study also investigates the indirect predictive powers of independent variables on students' motivational regulation through perceived engagement versus disaffection.

\section{Participants}

The research population consists of 690 ninth grade high school students who are attending five public Anatolia high schools in the Canakkale central districts. Stratified sampling is applied; two classrooms are randomly selected from each school. The students of each classroom are accepted as participants of the study. Sample size is determined according to criteria designated at a 95\% confidence level (Büyüköztürk, Çakmak, Akgün, Karadeniz, \& Demirel, 2011). Participants are 276 ninth grade high school students (148 girls and 126 boys) with a mean age of 14.8 years $(S D=.41)$. Different teachers teach each class. Students respond to the research instruments during their regular geography class hours under the supervision of the researcher and school counselors. The reasons this research is conducted during geography courses are: (1) this course is compulsory for $9^{\text {th }}$ grade,
(2) the ninth grade geography course is of interest both to students interested in science and those interested in social sciences, and (3) the scales must be completed with respect to a certain course.

\section{Instruments}

Teachers' Motivational Support Scale: The Teachers' Motivational Support Scale is a 24item Likert-type scale that measures students' perceptions of their teachers' motivational support behaviors with items adopted from various scales, it is used more specifically to assess teachers' support of autonomy, competence, and relatedness (Alfi, Assor, \& Katz, 2004; Assor et al., 2002; Reddy, Rhodes, \& Mulhall, 2003; Reeve \& Jang, 2006; Reeve, Jang, Carrell, Jeon, \& Barch, 2004; Skinner \& Belmont, 1993). The 51-item preliminary test of the scale is applied to 224 high school students as a pilot study. Items from the factor load that are under 40 after the exploratory factor analysis are left out of the scale. It is seen that the scale consists of three sub-dimensions: competence, autonomy, and relatedness support. The teacher competence support sub-dimension consists of 12 items. This is for the purpose of determining how the students perceive the teacher's support in terms of support (the teacher shows me how to solve the problems), contingency (I cannot know how the teacher will treat me), expectation (the teacher clearly expresses what they expect from me in class), and encouragement (the teacher makes an effort to convince me that I can overcome the most difficult tasks). The autonomy support subdimension has 6 items; it aims to determine the students' perceptions with respect to the teacher's support regarding offering options (the teacher offers many options as to how I will perform my tasks) and control (the teacher explains how I will use what I have learned). The relatedness support sub-dimension examines students' perceptions of teachers with respect to warmth (the teacher's speech and behavior are sincere) and care (the teacher spares time for me). The scale is a fourpoint Likert scale. The items are answered using options that range from "Not at all true $=1$ " to "Very true $=4$." Four items are expressed negatively in the scale, and are graded by reverse coding. The scale's reliability coefficients are computed as .89 for competence support, .90 for autonomy support, .83 for relatedness support, and .94 for the entire scale. The results of the verifying factor analysis for the scale's study group indicate that the three sub-dimensions structure proposed for the scale is 
suitable. The fit statistics indicate that the research model provides a reasonably good fit to the data $\left(\chi^{2}\right.$ $=473.39, d f=249, p=.00, R M S E A=.082, R M R=$ $.051, C F I=.90, G F I=.87, A G F I=.87, N F I=.81)$. For the study group, Cronbach's alpha internal consistency coefficients of the sub-dimensions of the scale are .89 for competence support, .89 for autonomy support, .82 for relatedness support, and .94 for the entire scale.

Motivational Regulation Scale: The Academic Selfregulation Scale is a scale developed for assessing the students' reasons for studying on a certain course. While developing the scale, the Ryan and Connell (1989) scale adapted by Vansteenkiste et al. (2009) was used. The items of the Vansteenkiste scale have been translated into Turkish and transformed so as to determine the reasons for studying a certain course. Items determined based on the results of interviews held with Turkish students are added to these items. For the obtained scale, which consists of 20 items, a pilot study is conducted with the participatory group of 204 students. The exploratory factor analysis is applied after the pilot study to determine that the scale comprise four factors and contains 12 items. The factor loads of the scale vary between .82 and .37 , and the Cronbach's alpha internal consistency coefficients of the sub-dimensions of the scale are .88 for intrinsic motivation (I'm studying because the course is interesting), .71 for identified regulation (I’m studying because what I learn will be helpful for me in the future), .66 for interjected regulation (I'm studying because otherwise I will feel bad), and .68 for external regulation (I'm studying because I'm worrying that I'm about to fail). Based on the theoretical explanations, the intrinsic and identified regulation sub-dimensions are combined to define the autonomy motivation, and the introjected and external regulation sub-dimensions are combined to define controlled motivation. The scale's Cronbach's alpha internal consistency coefficient is .86 for autonomy motivation and its Cronbach's alpha internal consistency coefficient is .72 for controlled motivation. The scale is a four-point Likert scale. The items are answered using options that range from "Not at all true $=1$ " to "Very true $=4$."

The results of the verifying factor analysis for the scale's study group indicate that the four subdimensions structure proposed for the scale is suitable. The fit statistics indicate that the research model provides a reasonably good fit to the data $\left(\chi^{2}=105.59, d f=48, p=.00, R M S E A\right.$ $=.074, R M R=.07, C F I=.93, G F I=.92, A G F I=$ $.87, N F I=.88)$. Chi-square to degrees of freedom ratio $\chi^{2} / d f=1.96$ is satisfactory. For the study group, the Cronbach's alpha internal consistency coefficients of the sub-dimensions of the scale are .88 for intrinsic motivation, .77 for identified regulation, .75 for introjected regulation, and .67 for external regulation. The reliability coefficient for the autonomy motivation section is .89 and the reliability coefficient of the controlled motivation dimension is .73.

Effective Participation: Effective Participation is a scale developed by the researcher to determine the students' engagement and disaffection to tasks on a certain course. In addition to the items in the scale developed by Wellborn (1991), a scale form consisting of 35 items is created as a result of semi-structured interviews held with students. The preliminary test of the scale is conducted on 260 high school students. The exploratory factor analysis reveals the fact that the scale consists of four factors and 16 items. The scale's factor loads vary between .49 and .72 . Four items of the scale measure behavioral engagement (When I'm in class, I volunteer for tasks if it's needed in class.), four items measure emotional engagement (When I'm in class, I feel good.), four items measure behavioral disaffection (When I'm in the class, I try to act like I'm involved.), and four items measure emotional disaffection (I feel nervous when my teacher asks for something). The Cronbach's alpha internal consistency coefficients of the subdimensions of the scale are .78 for behavioral engagement, .79 for emotional engagement, .74 for behavioral disaffection, and .74 for emotional disaffection. The scale's Cronbach's alpha internal consistency coefficient is .81 for engagement and its Cronbach's alpha internal consistency coefficient is .77 for disaffection. The scale is a four-point Likert scale. The items are answered using options that range from "Not at all true $=1$ " to "Very true $=4$."

The results of the verifying factor analysis for the scale's study group indicate that the four subdimensions structure proposed for the scale is suitable. The fit statistics indicate that the research model provides a reasonably good fit to the data $\left(\chi^{2}\right.$ $=74.62, d f=38, p=.00, R M S E A=.086, R M R=.04$, $C F I=.96, G F I=.90, A G F I=.92, N F I=.91, N N F I$ $=.91$ ). Chi-square to degrees of freedom ratio $\chi^{2} / d f$ $=1.96$ is satisfactory. The Cronbach's alpha internal consistency coefficients of the sub-dimensions of the scale are .78 for behavioral engagement, .83 for emotional engagement, .71 for behavioral disaffection, and .69 for emotional disaffection. The scale's Cronbach's alpha internal consistency 
coefficient is .84 for engagement and its Cronbach's alpha internal consistency coefficient is .81 for disaffection.

\section{Data Analysis}

As reported above, based on the results of the verifying confirmatory factor analysis of each scale, their structure is suitable for a research group. The measurement model that contains five latent variables and eleven observed variables is examined. Furthermore, the Pearson productmoment correlations coefficient is used to identify the relationships among variables. The theoretical model is tested using Lisrel 8.3 with maximum likelihood estimation. The Sobel test is used to test the significance of a mediation effect.

\section{Results}

The measurement model is examined by a confirmatory factor analysis prior to structural equation modeling. While teacher motivational support, autonomous motivation, controlled motivation, engagement, and disaffection are defined as latent variables, scores obtained from autonomy, competence, and relatedness subscales are defined as observed variables of teacher motivational support; scores obtained from intrinsic and identified regulation subscales are defined as observed variables of autonomous motivation; scores obtained from introjected and external regulation subscales are defined as observed variables of controlled motivation; scores obtained from behavioral and emotional engagement subscales are defined as observed variables of engagement; and scores obtained from behavioral and emotional disaffection subscales are defined as observed variables of disaffection. Thus, the measurement model is created by five latent variables and eleven observed variables. When the fit indexes are examined, the fit statistics indicate that the measurement model provides a reasonably good fit to the data $\left(\chi^{2}=47.85, d f=34, p=.059\right.$, $R M S E A=.038, R M R=.031, C F I=.99, G F I=.97$, $A G F I=.94, N F I=.97, N N F I=.99)$. Chi-square to degrees of freedom ratio $\chi^{2} / d f=1.40$ is satisfactory.

Before conducting the path model test, correlation sufficiency between related variables is examined. The results of the correlation analysis determine significant relationships between engagement versus disaffection and the related variables. As shown in Table 1, Pearson's correlation coefficients point out that engagement is positively associated with autonomous motivation $(r=.66, p<.01)$, autonomy support $(r=.64, p<.01)$ relatedness support of teacher $(r=.60 p<.01)$, and competence support of teacher $(r=-.57 p<.01)$. Pearson's correlation coefficients point out that students' engagement is negatively associated with controlled motivation $(r=.60 p<.01)$. On the other hand, disaffection is positively associated with controlled motivation $(r=$ $.49, p<.01)$. Furthermore, disaffection is negatively associated with autonomous motivation $(r=-.58$, $p<.01)$, autonomy support $(r=-.52, p<.01)$ relatedness support of teacher $(r=-.40 p<.01)$, and competence support of teacher $(r=-.39, p<.01)$.

The correlation values obtained from the research results are found to be sufficient for the model test. After finding relational coefficients between research variables, the model test aims to explain that effective participation is conducted. As mentioned above the model, specifically looks at the direct relationships of students' engagement versus disaffection and their perceptions of teachers' motivational support, and students' motivational regulations, as mediator variables, between students' engagement versus disaffection and their perceptions of teachers' motivational support style.

The fit statistics indicate that the research model provides a reasonably good fit to the data $\left(\chi^{2}=\right.$

\begin{tabular}{|c|c|c|c|c|c|c|c|c|}
\hline \multicolumn{9}{|c|}{$\begin{array}{l}\text { Table } 1 \\
\text { Mean, Standard Deviations and Bivariate Correlations of Research Variables }\end{array}$} \\
\hline & $M$ & $S D$ & 1 & 2 & 3 & 4 & 5 & 6 \\
\hline 1.Relatedness & 14.92 & 4.82 & & & & & & \\
\hline 2.Autonomy & 15.57 & 5.03 & $.77^{* *}$ & & & & & \\
\hline 3.Competence & 31.14 & 6.32 & $.69^{* *}$ & $.75^{* *}$ & & & & \\
\hline 4.Autonomous M. & 12.38 & 3.92 & $.44^{* *}$ & $.58^{* *}$ & $.49^{* *}$ & & & \\
\hline 5.Controlled M. & 15.42 & 4.82 & $-.15^{*}$ & $-.29^{* *}$ & $-.19^{\star *}$ & $-.45^{* *}$ & & \\
\hline 6.Engagement & 21.68 & 5.04 & $.60^{* *}$ & $.64^{* *}$ & $.57^{\star *}$ & $.66^{* *}$ & $-.38^{* *}$ & \\
\hline 7.Disaffection & 15.03 & 5.05 & $-.40^{* *}$ & $-.52^{\star *}$ & $-.39^{* *}$ & $-.58^{\star *}$ & $.49^{* *}$ & $-.68^{* *}$ \\
\hline
\end{tabular}

${ }^{*} p<.05 .{ }^{* *} p<.01$. 


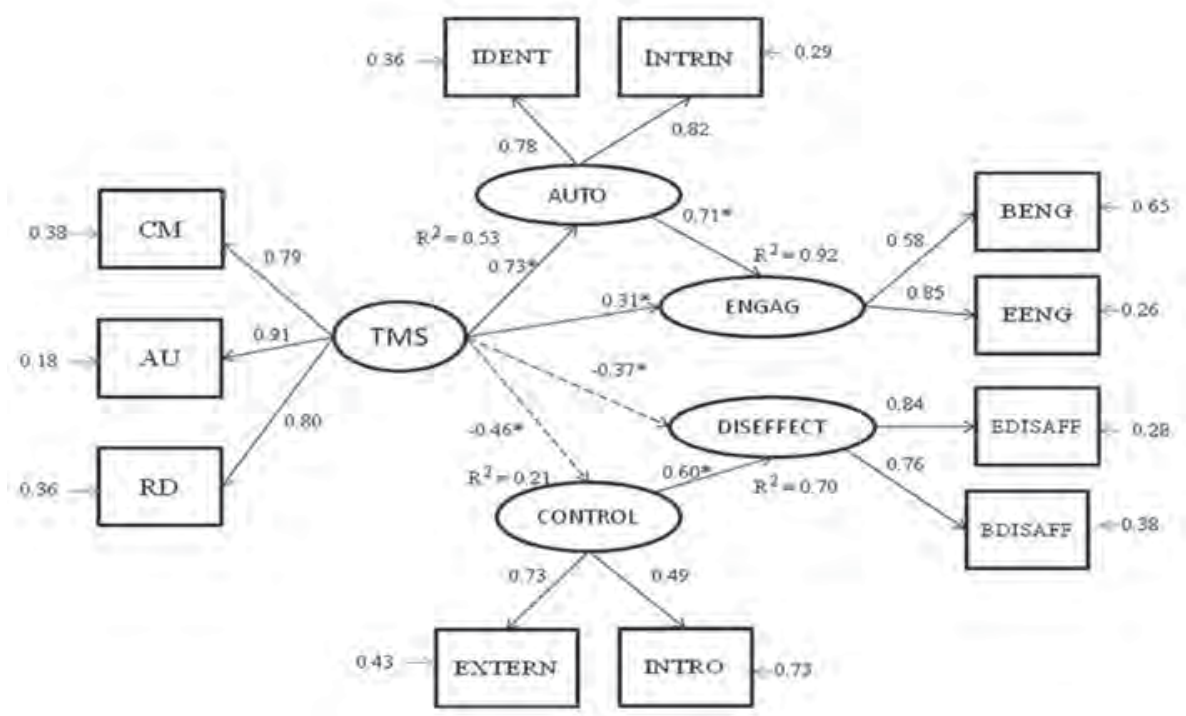

Figure 3: Path models for the relationship of teachers' motivational support style with engagement and disaffection.

74.62, $d f=38, p=.00, R M S E A=.086, R M R=.05$, $C F I=.96, G F I=.90, A G F I=.92, N F I=.91, N N F I=$ .91). Chi-square to degrees of freedom ratio $\chi^{2} / d f=$ 1.96 is satisfactory.

It is found that students' perceptions of teachers' motivational support are positively related to the autonomous motivation of students $(\beta=.73$; $t=8.04, p<.001)$, supporting hypothesis $\mathrm{H} 1$ and their engagement $(\beta=.31 ; t=1.97, p<.05)$, supporting H3. The students' perceptions of teachers' motivational support are negatively related to the controlling motivation of students $(\beta=-.46 ; t=-4.76, p<.001)$, supporting $\mathrm{H} 2$ and their disaffection $(\beta=-.37 ; t=-4.56, p<.001)$ supporting H4. Standardized regression coefficients indicate that students' perceptions of their teachers' motivational support explained $53 \%$ of the variance in autonomous motivation and $21 \%$ of the variance of controlled motivation. Furthermore, students' autonomous motivation is positively related to their engagement $(\beta=.71 ; t=2.25, p<.05)$, supporting $\mathrm{H} 5$, and students' controlling motivation is positively related to disaffection $(\beta=.60 ; t=3.86, p$ $<.001$ ), supporting H6.

The research results determine that the relationship between teachers' motivational support and students' engagement result from the indirect effect of autonomous motivation (tsobel $=2.13$ $p<.05)$. This result indicates the contribution of autonomous motivation at significant levels as a mediatory variable to the model. Together, autonomous motivation and motivational support style perceptions explain $92 \%$ of the variance of students' engagement. Therefore, H6 is supported. Furthermore, the research results determine that the relationship between teachers' motivational support and disaffection result from the indirect effect of controlled motivation (tsobel $=2.94 p<.05$ ). Together, controlled motivation and motivational support style perceptions explain $70 \%$ of the variance of students' disaffection. Therefore, engagement and disaffection are jointly determined by the indirect and direct influences of teachers' motivational support style.

\section{Discussion}

In this study, a model examining the effects of students' motivation orientation and teachers' motivational support on students' active participation in class is tested. The study reveals that motivational support provided by teachers has effects on the students' motivation orientation and active class participation. The results of the present study are consistent with previous research findings: students who perceive the teacher's motivational support positively are motivated autonomously (Assor et al., 2002; Bieg, Backes, \& Mittag, 2011; Black \& Deci, 2000; Goudas \& Biddle, 1994; Reeve, Bolt, \& Cai, 1999; Roth, Assor, KanatMaymon, \& Kaplan, 2007) and become engaged in the course (Jang, Revee, Ryan, \& Kim, 2009). In contrast, students who perceive the teacher's 
support negatively become subject to controlled motivation and experience disaffection (Jang et al., 2009; Ryan \& Connell, 1989).

The effect of teachers' support to students' autonomy, competence, and relatedness needs on students' motivation must be examined from multiple perspectives. Primarily, it is seen that teachers' motivational support affects autonomous motivation to a greater extent. However, teachers mostly feel powerless in affecting student motivation. In addition to studies indicating that teachers perceive motivation as a static student characteristic (Nespor, 1987), there are also studies showing that they believe student motivation to be determined by factors out of their control (Patrick \& Pintrich, 2001). Especially in high school, teachers are likely to believe that factors related to the student's previous experience, the school, and their parents have a greater effect on the student's motivation. Accordingly, the results of this study, as well as other studies, show that the effects that meeting students' psychological needs have on autonomous motivation and engagement are in line with the self-determination theory. Thus, this gives teachers the message that "there is much you can do." In fact, the important results of the selfdetermination theory in positively affecting student motivation are highly concrete and are achievable through teachers' individual efforts. Undoubtedly, developing relationships with students, creating options to support their autonomy, and creating a consistent and supportive structure require a certain amount of effort. However, the positive change the teacher may create through their individual efforts makes this work meaningful. Studies indicate that training teachers in affecting students' motivation cause change in a positive direction. There are studies that show that training teachers on student autonomy affects teachers' support for autonomy and any change that occurs in the teacher from this training will be perceived by the students (Reeve, 1998; Reeve et al., 2004). Self-determination theory offers teachers concrete suggestions that can be executed individually. Therefore, it should also be considered that being trained on how teachers affect student motivation according to self-determination theory may have a positive effect on teachers' perception of competence, which is known to be related with many teacher behaviors. The study indicates that a negative perception of teacher motivational support has an important impact on controlled motivation too. However, this effect is smaller compared with autonomous motivation. This may be due to the competitive and eliminative structure of our educational system. Thus, factors apart from teacher motivation style, which is especially effective on controlled motivation, need to be studied.

Another result of the study is that it demonstrates again the correlations between autonomous motivation and engagement and between controlled motivation and disaffection. This result is consistent with other studies in the field (Jang et al., 2009; Ryan \& Connell, 1989; Vallerand, 1997). What is important is not that a student performs a learning task, but under what motivational orientation they perform the task. The research shows positive correlations between engagement and academic success (Guthrie, Schafer, \& Huang, 2001) and a correlation between disaffection and negative outcomes, such as time management problems and anxiety. Accordingly, the basic product of motivation is seen as engagement.

The results of the study emphasize the importance of teacher motivational support in class. It may be concluded that teachers and teacher trainers should be educated on how to meet students' psychological needs in class. Furthermore, factors related to family, school, and class, which may have an effect on student motivational orientation, must be examined. Moreover, it can be concluded that studies based on learning and teaching processes with curriculum that concern the active class participation of students should be conducted in our country. 


\section{References}

Alfi, O., Assor, A., \& Katz, I. (2004). Learning to allow temporary failure: Potential benefits, supportive practices and teacher concerns. Journal of Education for Teaching, 30(1), 27-41.

Assor, A., Kaplan, H., \& Roth, G. (2002). Choice is good, but relevance is excellent: Autonomy-enhancing and suppressing teacher behaviours predicting students' engagement in schoolwork. British Journal of Educational Psychology, 72(2), 261-278.

Başaran, İ. E. (1982). Örgütsel davranış yönetimi. Ankara: A.Ü. Eğitim Bilimleri Fakültesi Yayını.

Benita, M., Roth, G., \& Deci, E. L. (2014). When are mastery goals more adaptive? It depends on experiences of autonomy support and autonomy. Journal of Educational Psychology, 106(1), 258-267.

Bieg, S., Backes, S., \& Mittag, W. (2011). The role of intrinsic motivation for teaching, teachers' care and autonomy support in students' self-determined motivation. Journal for Educational Research Online/Journal für Bildungsforschung Online, 3(1). Retrieved from http://www.j-f-b.de/index. php/jero/article/view/109/109

Black, A. E., \& Deci, E. L. (2000). The effects of instructors' autonomy support and students' autonomous motivation on learning organic chemistry: A self determination theory perspective. Science Education, 84(6), 740-756.

Büyüköztürk, Ş., Çakmak, E. K., Akgün, Ö. E., Karadeniz, Ş., \& Demirel, F. (2011). Bilimsel araştırma yöntemleri. Ankara: Pegem Akademi.

Deci, E. L., \& Ryan, R. M. (1987). The support of autonomy and the control of behavior. Journal of Personality and Social Psychology, 53(6), 1024-1037.

Deci, E. L., Schwartz, A. J., Sheinman, L., \& Ryan, R. M. (1981). An instrument to assess adults' orientations toward control versus autonomy with children: Reflections on intrinsic motivation and perceived competence. Journal of Educational Psychology, 73(5), 642-650.

Furrer, C., \& Skinner, E. A. (2003). Sense of relatedness as a factor in children's academic engagement and performance. Journal of Educational Psychology, 95, 148-162.

Good, T. L., \& Brophy, J. E. (1987). Looking in classrooms. New York, NY: Pearson Education Inc.

Goudas, M., \& Biddle, S. (1994). Perceived motivational climate and intrinsic motivation in school physical education classes. European Journal of Psychology of Education, 9, 241-250.

Guthrie, J. T., Schafer, W. D., \& Huang, C. (2001). Benefits of opportunity to read and balanced reading instruction for reading achievement and engagement: A policy analysis of state NAEP in Maryland. Journal of Educational Research, 94(3), 145-162.

Jang, H., Reeve, J., Ryan, R. M., \& Kim, A. (2009). Can self-determination theory explain what underlies the productive, satisfying learning experiences of collectivistically oriented Korean students? Journal of Educational Psychology, 101(3), 644-661.

Lynch, M., \& Cicchetti, D. (1997). Children's relationships with adults and peers: An examination of elementary and junior high school students. Journal of School Psychology, 35(1), 81-99.

Midgley, C., Feldlauffer, H., \& Eccles, J. (1989). Student/ teacher relations and attitudes toward mathematics before and after the transition to junior high school. Child Development, 60, 981-992.
Nespor, J. (1987). The role of beliefs in the practice of teaching. Journal of Curriculum Studies, 19, 317-328.

Patrick, H., \& Pintrich, P. R. (2001). Conceptual change in teachers' intuitive conceptions of learning, motivation, and instruction: The role of motivational and epistemological beliefs. In B. Torff \& R. Sternberg (Eds.), Understanding and teaching the intuitive mind: Student and teacher learning (pp. 117-144). Mahwah, NJ: Lawrence Erlbaum Associates.

Reddy, R., Rhodes, J. E., \& Mulhall, P. (2003). The influence of teacher support on student adjustment in the middle school years: A latent growth curve study. Development and Psychopathology, 15(01), 119-138.

Reeve, J. (1998). Autonomy support as an interpersonal motivating style: Is it teachable? Contemporary Educational Psychology, 23(3), 312-330.

Reeve, J., \& Jang, H. (2006). What teachers say and do to support students' autonomy during a learning activity. Journal of Educational Psychology, 98, 209-218.

Reeve, J., Bolt, E., \& Cai, Y. (1999). Autonomy-supportive teachers: How they teach and motivate students. Journal of Educational Psychology, 91, 537-548.

Reeve, J., Jang, H., Carrell, D., Jeon, S., \& Barch, J. (2004). Enhancing students' engagement by increasing teachers' autonomy support. Motivation and Emotion, 28(2), 147-169.

Roth, G., Assor, A., Kanat-Maymon, Y., \& Kaplan, H. (2007). Autonomous motivation for teaching: How selfdetermined teaching may lead to self-determined learning. Journal of Educational Psychology, 99, 761-774.

Ryan, R. M., \& Deci, E. L. (2000). Intrinsic and extrinsic motivations: Classic definitions and new directions. Contemporary Educational Psychology, 25, 5467. doi:10.1006/ceps.1999.1020

Ryan, R. M., \& Connell, J. P. (1989). Perceived locus of causality and internalization: examining reasons for acting in two domains. Journal of Personality and Social Psychology, 57(5), 749-761.

Ryan, R. M., Stiller, J. D., \& Lynch, J. H. (1994). Representations of relationships to teachers, parents, and friendsas predictors of academic motivation and selfesteem. Journal of Early Adolescence, 14, 226-249.

Sierens, E., Vansteenkiste, M., Goossens, L., Soenens, B., \& Dochy, F. (2009). The synergistic relationship of perceived autonomy support and structure in predictor of self-regulated learning. British Journal of Educational Psychology, 79(1), 57-68.

Skinner, E. A., \& Belmont, M. J. (1993). Motivation in the classroom: Reciprocal effects of teacher behavior and student engagement across the school year. Journal of Educational Psychology, 85, 571-581.

Skinner, E. A., Kindermann, T. A., Connell, J. P., \& Wellborn, J. G. (2009). Engagement as an organizational construct in the dynamics of motivational development. In K. Wentzel \& A. Wigfield (Eds.), Handbook of motivation in school (pp. 223-245). Malwah, NJ: Erlbaum.

Skinner, E. A., Wellborn, J. G., \& Connell, J. P. (1990). What it takes to do well in school and whether I've got it: A process model of perceived control and children's engagement and achievement in school. Journal of Educational Psychology, 82(1), 22-32.

Skinner, E., Furrer, C., Marchand, G., \& Kindermann, T. (2008). Engagement and disaffection in the classroom: Part of a larger motivational dynamic? Journal of Educational Psychology, 100(4), 765-781. 
Stefanou, C. R., Perencevich, K. C., DiCintio, M., \& Turner, J. C. (2004). Supporting autonomy in the classroom: Ways teachers encourage student decision making and ownership. Educational Psychologist, 39(2), 97-110.

Tucker, C. M., Zayco, R. A., Herman, K. C., Reinke, W. M., Trujillo, M., Carraway, K. ... Ivery P. D. (2002). Teacher and child variables as predictors of academic engagement among low-income African American children. Psychology in the Schools, 39, 477-488.

Vallerand, R. J. (1997). Toward a hierarchical model of intrinsic and extrinsic motivation. In M. P. Zanna (Ed.), Advances in experimental social psychology (Vol. 29, pp. 271-360). San Diego, CA: Academic Press.
Vansteenkiste, M., Sierens, E., Soenens, B., Luyckx, K., \& Lens, W. (2009). Motivational profiles from a selfdetermination perspective: The quality of motivation matters. Journal of Educational Psychology, 101(3), 671-688.

Vansteenkiste, M., Zhou, M., Lens, W., \& Soenens, B. (2005). Experiences of autonomy and control among Chinese learners: Vitalizing or immobilizing? Journal of Educational Psychology, 97(3), 468-483.

Wellborn, J. G. (1991). Engaged and disaffected action: The conceptualization and measurement of motivation in the academic domain (Doctoral thesis). Available from ProOuest Dissertations and Theses database. (UMI No. 9218563) 